\title{
GMR
}

\section{Identification of polymorphisms and transcriptional activity of the proto-oncogene KIT located on both autosomal and B chromosomes of the Chinese raccoon dog}

\author{
Y.M. Li' ${ }^{1}$, Y. Zhang ${ }^{1}$, W.J. Zhu' ${ }^{1}$ S.Q. Yan ${ }^{1}$ and J.H. Sun ${ }^{2}$ \\ ${ }^{1}$ College of Animal Science, Jilin University, Changchun, China \\ ${ }^{2}$ College of Animal Science and Veterinary Medicine, Qingdao Agricultural University, \\ Qingdao, China \\ Corresponding author: S.Q. Yan \\ E-mail: yansq@jlu.edu.cn \\ Genet. Mol. Res. 15 (1): gmr.15017398 \\ Received August 7, 2015 \\ Accepted October 29, 2015 \\ Published February 5, 2016 \\ DOI http://dx.doi.org/10.4238/gmr.15017398
}

\begin{abstract}
B chromosomes are dispensable and co-exist with autosomal and sex chromosomes. The karyotype of the Chinese raccoon dog (Nyctereutes procyonoides procyonoides) comprises 0-4 B chromosomes. The proto-oncogene $K I T$ is found on all $B$ chromosomes of the Chinese raccoon dog. In the present study, partial DNA and mRNA sequences of $K I T$ were amplified and sequenced from four individuals containing $B$ chromosomes. Sequence analyses revealed that polymorphisms including single nucleotide polymorphisms (SNPs) and inserts/deletions were rich in the KIT gene of Chinese raccoon dog at the genomic level. However, no polymorphism was detected at the mRNA level. A comparison of mRNA sequences from Chinese raccoon dogs with the corresponding sequences derived from arctic fox and dog, which do not contain B chromosomes, revealed the mRNA sequences of the 10 SNPs to be identical between these three species. Therefore, these findings suggest that KIT located on the B chromosomes in Chinese raccoon dog lacks transcriptional activity.
\end{abstract}

Key words: Chinese raccoon dog; KIT gene; Polymorphism; B chromosome 


\section{INTRODUCTION}

B chromosomes, also known as supernumerary, accessory, or extra chromosomes, are dispensable genetic elements, present in addition to the standard karyotype (A chromosomes, including autosomal and sex chromosomes) (Muñoz-Pajares et al., 2011). B chromosomes have been found in many eukaryotic organisms, including plants, animals, and fungi (Yoshida et al., 2011). The number of $B$ chromosomes in each cell may vary among different tissues, individuals, and populations because of their mitotic instability and the existence of specific accumulation mechanisms acting during gametogenesis (Jones and Houben, 2003). B chromosomes were thought to be heterochromatic and inert, lacking active genes and having no effect on the host phenotype. B chromosomes do not pair with any of the standard A chromosomes during meiosis and have irregular modes of inheritance. At the DNA level, B chromosomes are usually enriched in tandem repeated sequences (Potapov et al., 1990), long interspersed nuclear elements, short interspersed nuclear elements (Peppers et al., 1997), interstitial telomeric sequences (Wurster-Hill et al., 1988), ribosomal DNA (rDNA) clusters (Stitou et al., 2000; Szczerbal and Switonski, 2003), and others. In some species, rDNA genes located on the B chromosomes have been demonstrated to exhibit transcriptional activity (Leach et al., 2005; Ruiz-Estevez et al., 2012). In addition, some protein-coding genes have also been identified on the B chromosomes of certain species (Miao et al., 1991; Lamatsch et al., 2011; Yoshida et al., 2011; Martis et al., 2012). Some of these are thought to have functional significance for their host (Miao et al., 1991; Yoshida et al., 2011) and exhibit transcriptional activity (Trifonov et al., 2013).

The karyotype of the Chinese raccoon dog (Nyctereutes procyonoides procyonoides) comprises 5 submetacentric autosomes, 21 acrocentric autosomes, and up to 4 B chromosomes (Switonski et al., 2003). The B chromosomes range in size and are characterized as $\mathrm{Bi}$, Bii, and Biii types (Becker et al., 2011). The proto-oncogene KIT is present on all B chromosomes of the Chinese raccoon dog, in addition to chromosome 6 (Graphodatsky et al., 2005; Yudkin et al., 2007; Becker et al., 2011). The proto-oncogene KIT is also localized on all B chromosomes of red fox and the structure and sequence of the B-specific KIT were found to be highly conserved (Graphodatsky et al., 2005; Yudkin et al., 2007).

KIT (also c-kit) encodes a cell-surface tyrosine kinase specific for the mast/stem cell growth factor, which is critical for proliferation and cell differentiation of hematopoietic, melanoblast, and primordial germ cells (Ashman, 1999; Roskoski, 2005). KIT is the first protein-coding autosomal gene to be found on mammalian B chromosomes (Graphodatsky et al., 2005). To investigate whether KIT located on the B chromosomes exhibits transcriptional activity in the Chinese raccoon dog, we cloned, sequenced, and compared the partial sequence of KIT at both genomic DNA and mRNA levels.

\section{MATERIAL AND METHODS}

All animal experiments were performed in accordance with the guidelines on animal care established by the Jilin University Animal Care and Use Committee. Seven tissue samples (including muscle, brain, liver, kidney, heart, lung, and spleen) were collected from four farmed Chinese raccoon dogs containing 0-4 B chromosomes per cell (Li et al., 2013).

Genomic DNA was isolated from liver tissue using the TIANamp Genomic DNA Kit (TIANGEN, Beijing, China). Total RNA was isolated from the frozen tissues using TRIzol (Invitrogen, Carlsbad, CA, USA) according to the manufacturer protocol and was followed by digestion with RNase-free DNase I according to the manufacturer instructions (Promega, Madison, WI, USA). 
First-strand cDNA was generated with PrimeScriptTM RT reagent Kit (TaKaRa, Dalian, China). In order to amplify exons 18,19 , and 20 of $K I T$ from the Chinese raccoon dog, a pair of primers (CKIT-F1:5'-GGTAAAAGGCCTTTGTGAGATG-3'; CKIT-R1:5'-CTGCTTGAGCCAAGGATAGAAG3') was designed based on the nucleotide sequence of canine KIT (accession No. NC_006595). A long-range PCR procedure was performed using genomic DNA as a template. The PCR was carried out in a total volume of $25 \mu \mathrm{L}$ containing $0.5 \mu \mathrm{L}$ genomic DNA, $5 \mu \mathrm{M}$ each primer (CKIT-F1 and CKIT-R1), $0.2 \mathrm{mM}$ dNTPs, and $1 \mathrm{U}$ LA Taq polymerase (TaKaRa). PCR conditions were as follows: a 3-min denaturation step at $95^{\circ} \mathrm{C}, 30$ cycles of $30 \mathrm{~s}$ at $94^{\circ} \mathrm{C}, 30 \mathrm{~s}$ at $60^{\circ} \mathrm{C}$, and $2 \mathrm{~min}$ at $72^{\circ} \mathrm{C}$, followed by a final extension of $15 \mathrm{~min}$ at $72^{\circ} \mathrm{C}$. The amplified products were visualized on a $1.5 \%$ agarose gel stained with ethidium bromide. PCR products were cloned into pGEM ${ }^{\circledast}-T_{\text {Vector }}$ (Promega) and used to transform DH5 $\alpha$ competent cells. Clones containing inserts were randomly chosen for DNA sequencing.

Tocharacterize KIT polymorphisms in the Chinese raccoon dog at the mRNAlevel, a newset of primers (CKIT-F2: 5'-ATGGAAGATGATGAGTTGGCT-3'; CKIT-R2: 5'-TCACACATCTTCGTGTAC$3^{\prime}$ ) was designed based on the KIT mRNA sequence of the Chinese raccoon dog (accession No. KM083121). RT-PCR was also performed using cDNA generated from brain, muscle, kidney, heart, liver, lung, and spleen tissues. The reaction system and conditions of RT-PCR were the same as those described above. PCR products were purified and sequenced directly.

\section{RESULTS AND DISCUSSION}

Following PCR amplification for exons $18-20$ and the flanking sequence of $K I T$ from genomic DNA of Chinese raccoon dogs, two bands were unexpectedly detected on $1.5 \%$ agarose gel from all four individuals (Figure 1). Sequencing analysis revealed the bigger fragment (KIT-g-1) to be $1463 \mathrm{bp}$ in size and the other (KIT-g-2) to be $1016 \mathrm{bp}$. Alignment indicated that the difference in length is due to the insertion or deletion of a single tandem repeat sequence of (CTTTT), and there were 32 single nucleotide polymorphisms (SNPs) between KIT-g-1 and KIT-g-2 (Figure 2). Ten of those SNPs were located in the three exons studied (18, 19, and 20 of KIT). Analysis of the putative amino acid sequence revealed that nine of the 10 SNPs were mis-synonymous substitutions. BLASTn analysis using the NCBI GenBank database (http://www.ncbi.nlm.nih.gov) showed that the coding sequence deduced from KIT-g-2 was $100 \%$ identical to the corresponding sequence of KIT of arctic fox (No. KF530833) and dog (No. AY313776). Contrary to the results obtained from B chromosomes of red fox, sequences of the B-specific KIT were found to be highly homologous to that of the A chromosome (Graphodatsky et al., 2005).

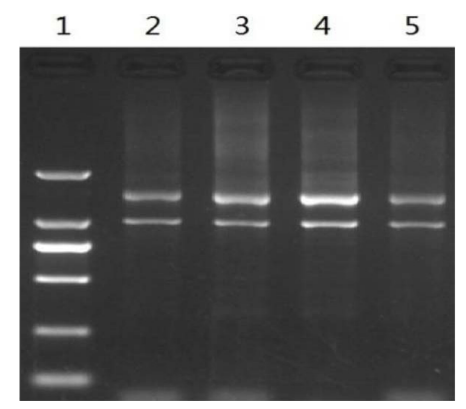

Figure 1. Agarose gel electrophoresis of PCR products amplified by primer set CKIT-F1 and CKIT-R1. Lane $1=$ DL2000 marker. Lanes 2-5 = four Chinese raccoon dogs with B chromosomes. 


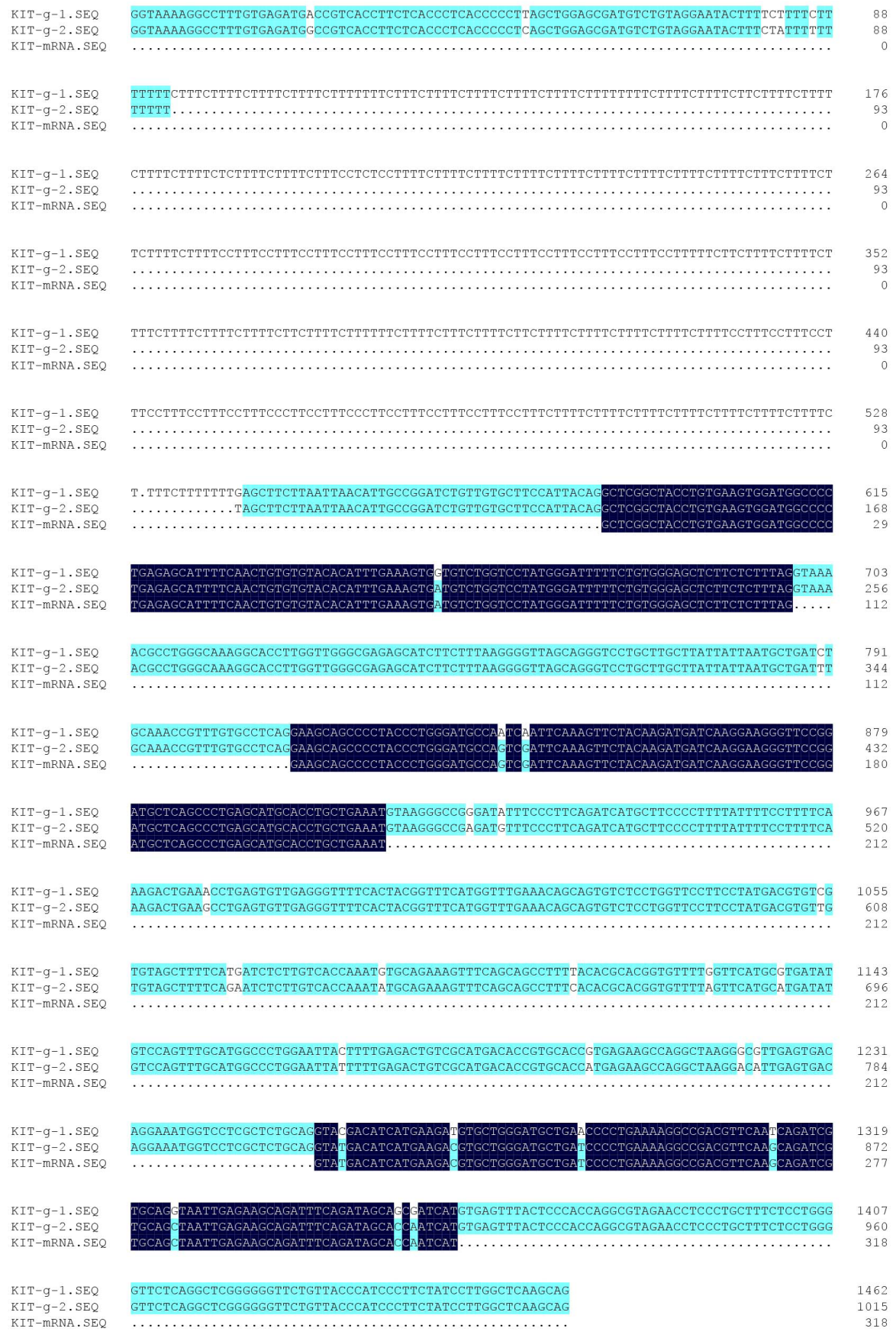

Figure 2. Alignment of nucleotide sequences from KIT-g-1, KIT-g-2, and KIT-mRNA. KIT-g-1 and KIT-g-2 was amplified using CKIT-F1 and CKIT-R1 as primers and genomic DNA as templates, KIT-mRNA was amplified using CKIT-F2 and CKIT-R2 as primers and CDNA as templates. 
RT-PCR was first carried out using cDNA synthesized from total RNA extracted from the brain tissue of four Chinese raccoon dogs. A 663-bp fragment was obtained. Direct sequencing of the RT-PCR product showed that no polymorphic sites were found in the RT-PCR amplification products, and that the mRNA sequence (KIT-mRNA) is $100 \%$ identical to that of KIT-2-g (Figure 2). To further exclude the possibility of tissue-specific transcriptional activity, RT-PCR amplification was conducted on total RNA isolated from liver, muscle, heart, lung, spleen, and kidney. No polymorphic transcripts were found from any of the tissues used in this study.

Several copies of KIT paralogs have previously been found on B chromosomes in the Chinese raccoon dog, whereas there is a single copy on chromosome 6 (Becker et al., 2011). Sequence alignment between the Chinese raccoon dog, arctic fox, silver fox, and dog suggested it was possible to distinguish paralogs on the B chromosome from those on the A chromosome. Therefore, we presumed that KIT-2-g was from chromosome 6 of the Chinese raccoon dog and that the insertion of a tandem repeat sequence in intron 17 (KIT-1-g) was B-specific. RT-PCR analysis indicated that the B-located KIT sequence identified in this study was not transcribed.

The high sequence variation of KIT shown from B chromosomes, compared to that on an autosomal chromosome, suggests that purifying selection was relaxed for KIT located in the B chromosomes, as expected if B chromosomes were genetically inactive.

In summary, KIT is rich in polymorphisms including SNPs and insert/deletions between B and A chromosomes in Chinese raccoon dogs. However, KIT located on the B chromosomes has no transcriptional activity.

\section{Conflicts of interest}

The authors declare no conflict of interest.

\section{ACKNOWLEDGMENTS}

Research supported by project of the National Natural Science Foundation of China (\#31401979) and the Fundamental Research Funds of Jilin University (\#200903332).

\section{REFERENCES}

Ashman LK (1999). The biology of stem cell factor and its receptor C-kit. Int. J. Biochem. Cell Biol. 31: $1037-1051$. http://dx.doi.org/10.1016/S1357-2725(99)00076-X

Becker SE, Thomas R, Trifonov VA, Wayne RK, et al. (2011). Anchoring the dog to its relatives reveals new evolutionary breakpoints across 11 species of the Canidae and provides new clues for the role of $\mathrm{B}$ chromosomes. Chromosome Res. 19: 685-708.http://dx.doi.org/10.1007/s10577-011-9233-4

Graphodatsky AS, Kukekova AV, Yudkin DV, Trifonov VA, et al. (2005). The proto-oncogene C-KIT maps to canid B-chromosomes. Chromosome Res. 13: 113-122.http://dx.doi.org/10.1007/s10577-005-7474-9

Jones N and Houben A (2003). B chromosomes in plants: escapees from the A chromosome genome? Trends Plant Sci. 8: 417-423.http://dx.doi.org/10.1016/S1360-1385(03)00187-0

Lamatsch DK, Trifonov V, Schories S, Epplen JT, et al. (2011). Isolation of a cancer-associated microchromosome in the spermdependent parthenogen Poecilia formosa. Cytogenet. Genome Res. 135: 135-142.http://dx.doi.org/10.1159/000331271

Leach CR, Houben A, Field B, Pistrick K, et al. (2005). Molecular evidence for transcription of genes on a B chromosome in Crepis capillaris. Genetics 171: 269-278.http://dx.doi.org/10.1534/genetics.105.043273

Li YP, Liang YY, Ma ZF, Zhu YF, et al. (2013). Comparison of Chromosome number among three colors of Ussuri raccoon dog. J. Anhui Agric. Sci. 41: 8188-8191.</jrn>

Martis MM, Klemme S, Banaei-Moghaddam AM, Blattner FR, et al. (2012). Selfish supernumerary chromosome reveals its origin as a mosaic of host genome and organellar sequences. Proc. Natl. Acad. Sci. USA 109: 13343-13346. http://dx.doi.org/10.1073/pnas.1204237109 
Miao VP, Covert SF and VanEtten HD (1991). A fungal gene for antibiotic resistance on a dispensable ("B") chromosome. Science 254: 1773-1776.http://dx.doi.org/10.1126/science. 1763326

Muñoz-Pajares AJ, Martínez-Rodríguez L, Teruel M, Cabrero J, et al. (2011). A single, recent origin of the accessory B chromosome of the grasshopper Eyprepocnemis plorans. Genetics 187: 853-863. http://dx.doi.org/10.1534/genetics.110.122713

Peppers JA, Wiggins LE and Baker RJ (1997). Nature of B chromosomes in the harvest mouse Reithrodontomys megalotis by fluorescence in situ hybridization (FISH). Chromosome Res. 5: 475-479.http://dx.doi.org/10.1023/A:1018421114607

Potapov VA, Solov'ev VV, Romashchenko AG, Sosnovtsev SV, et al. (1990). [Features of the structure and evolution of complex, tandemly organized Bsp-repeats in the fox genome. I. Structure and internal organization of the BamHI-dimer]. Mol. Biol. (Mosk.) 24: 1649-1665.

Roskoski R Jr. (2005). Structure and regulation of Kit protein-tyrosine kinase--the stem cell factor receptor. Biochem. Biophys. Res. Commun. 338: 1307-1315.http://dx.doi.org/10.1016/j.bbrc.2005.09.150

Ruiz-Estévez M, López-León MD, Cabrero J and Camacho JPM (2012). B-chromosome ribosomal DNA is functional in the grasshopper Eyprepocnemis plorans. PLoS One 7: e36600.http://dx.doi.org/10.1371/journal.pone.0036600

Stitou S, Díaz de La Guardia R, Jiménez R and Burgos M (2000). Inactive ribosomal cistrons are spread throughout the B chromosomes of Rattus rattus (Rodentia, Muridae). Implications for their origin and evolution. Chromosome Res. 8: 305311.http://dx.doi.org/10.1023/A:1009227427575

Switonski M, Rogalska-Niznik N, Szczerbal I and Baer M (2003). Chromosome polymorphism and karyotype evolution of four canids: the dog, red fox, arctic fox and raccoon dog. Caryologia 56: 375-385. http://dx.doi.org/10.1080/00087114.2003.10589348</jrn>

Szczerbal I and Switonski M (2003). B chromosomes of the Chinese raccoon dog (Nyctereutes procyonoides procyonoides Gray) contain inactive NOR-like sequences. Caryologia 56: 213-216. http://dx.doi.org/10.1080/00087114.2003.10589327</jrn>

Trifonov VA, Dementyeva PV, Larkin DM, O'Brien PC, et al. (2013). Transcription of a protein-coding gene on B chromosomes of the Siberian roe deer (Capreolus pygargus). BMC Biol. 11: 90.http://dx.doi.org/10.1186/1741-7007-11-90

Wurster-Hill DH, Ward OG, Davis BH, Park JP, et al. (1988). Fragile sites, telomeric DNA sequences, B chromosomes, and DNA content in raccoon dogs, Nyctereutes procyonoides, with comparative notes on foxes, coyote, wolf, and raccoon. Cytogenet. Cell Genet. 49: 278-281.http://dx.doi.org/10.1159/000132677

Yoshida K, Terai Y, Mizoiri S, Aibara M, et al. (2011). B chromosomes have a functional effect on female sex determination in Lake Victoria cichlid fishes. PLoS Genet. 7: e1002203.http://dx.doi.org/10.1371/journal.pgen.1002203

Yudkin DV, Trifonov VA, Kukekova AV, Vorobieva NV, et al. (2007). Mapping of KIT adjacent sequences on canid autosomes and B chromosomes. Cytogenet. Genome Res. 116: 100-103.http://dx.doi.org/10.1159/000097424 